\title{
Dimensional Characteristics of Knitted Fabrics Made from 100\% Cotton and Cotton/Elastane Yarns
}

\author{
Dereje Berihun Sitotaw \\ Textile Engineering, Bahir Dar University, Ethiopian Institute of Textile and Fashion Technology (EiTEX), Bahir Dar, Ethiopia \\ Correspondence should be addressed to Dereje Berihun Sitotaw; dere96@yahoo.com
}

Received 5 April 2018; Revised 8 May 2018; Accepted 17 May 2018; Published 29 May 2018

Academic Editor: Yuezhong Meng

Copyright (C) 2018 Dereje Berihun Sitotaw. This is an open access article distributed under the Creative Commons Attribution License, which permits unrestricted use, distribution, and reproduction in any medium, provided the original work is properly cited.

\begin{abstract}
The dimensional characteristics such as loop length (l), wales per centimeter (wpc), courses per centimeter (cpc), stitch density $(\mathrm{s})$, tightness factor $(\mathrm{K})$, loop shape factor $(\mathrm{R})$ and take-up rate $(\mathrm{T})$ of single jersey, 1xlrib, 1x1 interlock, single pique, and twothread fleece knitted fabrics made from $100 \%$ cotton and cotton/elastane yarns (5\% elastane yarn content) are investigated in this research. Dimensional properties of knitted fabrics are an important property and determine the materials consumption during production, productions parameter, and applications of different knitted structures. The sample fabrics have been conditioned for 24 hours at $20 \pm 1^{\circ} \mathrm{C}$ temperature and $65 \pm 2 \%$ relative humidity. The specimens used for sampling are determined as per the test standards described in the paper for each yarn type, property, and structure. As observed in the result, the properties are related to each other. It is found that the loop length, wpc, $\mathrm{cpc}$, stitch density, tightness factor, loop shape factor and take-up rate of single jersey, 1xlrib, 1xlinterlock, single pique, and two-thread fleece knitted fabrics made from $100 \%$ cotton and cotton/elastane yarns are significantly influenced by the presence of an elastane yarn. The loop length of single jersey, 1xlrib, and interlock knitted fabrics made from elastane yarns reduced while the single pique and fleece increased. Similarly, other dimensional properties are significantly influenced by the yarn types used during knitting.
\end{abstract}

\section{Introduction}

Knitted fabrics are produced by interlooping of yarns and showed increasing demand for their shape fitting, smoothness, flexibility, elasticity, and good elastic recovery. But, all knitted fabrics may not have these properties equally. These properties are determined by raw material types and characteristics, knitting machine parameters, and type of knit structures. The knitted fabrics are textile structures made of elastic interconnected stitches and characterized by two perpendicular directions, the direction of stitches courses on the direction of stitches courses in vertical direction[1].

Knitted goods of all kinds are generally popular because of their flexibility and ability to adapt as well as stretch them to a particular shape when worn and because of their general comfortable wear. The dimensional stability of knitted structures from mostly conventional yarns together with other physical properties has been one of the most extensively discussed subjects in research [2-4]. The dimensional stability of the knitted fabrics is reflected in the capability of the products made from spandex, of maintaining the shape and dimensions in the predetermined limits, after several cycles of washing-wearing process [5].

The generic name "spandex" as defined by FTC is "A manufactured fiber in which fiber forming substance is a long chain synthetic polymer comprised of at least $85 \%$ of a segmented polyurethane" [6]. The name "spandex" is the anagram of the word expands [7]. Chemically, spandex is synthetic linear macromolecule with a long chain containing alternating hard and soft segments linked by $[-\mathrm{NH}-\mathrm{CO}-$ $\mathrm{O}-$ ] urethane bonds. The soft structure is of polyurethane block copolymer which delivers elasticity to fiber, while hard chain segment contributes molecular interaction force to fiber which confirms fiber strength and long term stability [8]. Elastane is used in all areas where a high degree of permanent elasticity is required, for example, in tights, sportswear, swimwear, corsetry, and woven and knitted fabrics. Elastane is a prerequisite for fashionable or functional apparel, intended to cling to the body making it remain comfortable. Worldwide spandex consumption and growth 
is $30-40 \%$ per year and is expected to grow high. Asian countries have a share of nearly $60 \%$ of world consumption and contribute $25 \%$ of worldwide spandex growth per year [9]. The important loop dimensions are loop length, loop width (wale spacing), and loop height (course spacing). Besides the loop dimensions, which have a great effect on fabric quality and the physical, mechanical, and dimensional properties of the cotton single jersey knitted fabric, there are the machine gauge, needle type, cam type, yarn feeding system, number of feeders, take down system, cloth rolling or spreading, monitoring and control systems, etc. [10-12].

Reference [13] investigated the dimensional and physical properties of cotton/spandex single jersey fabrics and compared the results with fabrics knitted from cotton alone. It was apparent that as the amount of spandex increased the loop length value remained nearly the same and the course and wale spacing decreased.

As the Lycra extension percent reached $232 \%$ in the case of the half plating fabrics, the course density increased by $40 \%$ and the wale density increased by $6 \%$ [14-16]. The results obtained in the present work indicated that the amount of elastane has a significant effect on dimensional and elastic properties of cotton/elastane plated plain knitted fabric [17].

Textured threads increase thickness and area density of knits. Higher course and wale densities have knits plated with elastane thread under the same machine set stitch lengths (due to yarn relaxation) than knits from pure yarns. Loop length becomes shorter and density of knit increases so knit is more tightened and heavier $[2,14]$.

As reviewed in different literatures, the researchers study the effect of elastane yarn on single jersey knitted fabrics only. These may not help conclude effect of elastane on other knitted fabrics, those produced on two sets of needles and others produced as derivatives of single jersey. In this research single jersey, single pique, two-thread fleece, 1x1rib, and 1xlinterlock knitted fabrics made from 100\% cotton and cotton/elastane yarns are investigated for their some of dimensional properties.

\section{Material and Experiments}

2.1. Materials. $100 \%$ cotton and cotton/elastane blend yarns are used for this study. An elastane accounts for about 5\% contents (40denier $=133 \mathrm{Ne}$ ) while cotton accounts for $95 \%$ content $(35 \mathrm{Ne})$ in the $28 \mathrm{Ne}$ combed cotton/elastane blended yarn (cotton/elastane $=95 / 5 \%$ ) and an elastane yarn is fed to the needles as naked filament with the cotton yarn in the same yarn feeder (carrier) but is neither plied nor core spun with cotton. Cotton fiber harvested from Upper AwashEthiopia has $28 \mathrm{~mm}$ staple lengths, 12.8 short fiber index, 300 neps, 4.06 trash percent, and 4.2 micronaire fineness. The yarns used for this study are $100 \%$ cotton and cotton/elastane blended. The cotton yarn has $750 \mathrm{~m}^{-1}$ twist, $28 \mathrm{Ne}$ count, 9.21\% U\%, 11.70 CVM, 0 thin-50\%, 33.6 thick+50\%, 29.8 Neps $+200 \%$, and 63.4 total imperfection percent. The single jersey, single pique, and two-thread fleece are produced by the single-bed circular knitting machine with $30 \mathrm{rpm}$, 34" diameter, 2976 needles, 4 cam tracks, and 108 feeders. 1x1Rib/interlock is produced by double-bed circular knitting machine with 20/14 rpm, 30" diameter, 2630 needles, 94/112 feeders, and 1/2 cam tracks, respectively. The study was carried out by keeping these materials and their parameters constant except for the yarn's (raw material type).

In the single jersey, 1xlrib, interlock, single pique, and fleece knitted fabrics, the loop lengths were set equal in the knitting machine. But, during the knitting process the fabrics will have different loop lengths due to transferring of the loop and staying idle in the rib and interlock knitting machines and the floats at the technical back of fleece knitted fabrics. There are 28 needles per inch in a cylinder in single jersey, single pique, and fleece. In 1xlrib knitting machines there are 18 needles per inch in cylinder and 18 needles per inch in dial. In interlock knitting machines there are 24 needles per inch in cylinder and 24 needles per inch in dial. The working principle and arrangement of needles in 1xlrib and interlock knitting machines are different in gaiting [18].

2.2. Experiments. Single jersey, $1 x 1$ rib, interlock, single pique, and fleece knitted fabrics were produced for this study. Loop length, wales per centimeter (wpc) and courses per centimeter (cpc) of single jersey, 1xlrib, interlock, single pique, and two-thread fleece knitted fabrics made from $100 \%$ cotton and cotton/elastane yarns have been measured using crimp tester (loop length) and pick glass (wpc and cpc). Other properties such as stitch density, tightness factor, loop shape factor, and take-up rate of knitted fabrics are calculated from measured properties of knitted fabrics.

(i) The yarn properties such as U\% (irregularity), CVM (coefficient of variation in mass), thin and thick places, and the amount of Neps in cotton yarn are tested using Uster tester 5 machine and Uster testing standards.

(ii) The loop length, wpc and cpc of single jersey, 1xlrib, interlock, single pique, and fleece knitted fabrics have been measured using crimp tester and pick glass, respectively.

(iii) The stitch density of these fabrics is calculated from the measured results of $\mathrm{wpc}$ and cpc. So, Stitch density $(S)=\mathrm{wpc} * \mathrm{cpc}$.

(iv) The tightness factors of knitted fabrics are calculated from the measured results of yarn count (Tex) and loop length (1). So, Tightness factor $(k)=\sqrt{\text { Tex }} / 1$.

(v) The loop shape factors of single jersey, 1xlrib, interlock, single pique, and two-thread fleece knitted fabrics are calculated from the measured result of course per unit length (cpc) and wales per unit length (wpc). So, Loop shape factor $(R)=\mathrm{cpc} / \mathrm{wpc}$.

(vi) Take-up rates of knitted fabrics are calculated from the measured and calculated results of loop length (l) and loop pitch. So,

Take - up rate $(T)=\frac{1}{\text { loop pitch }}$ 


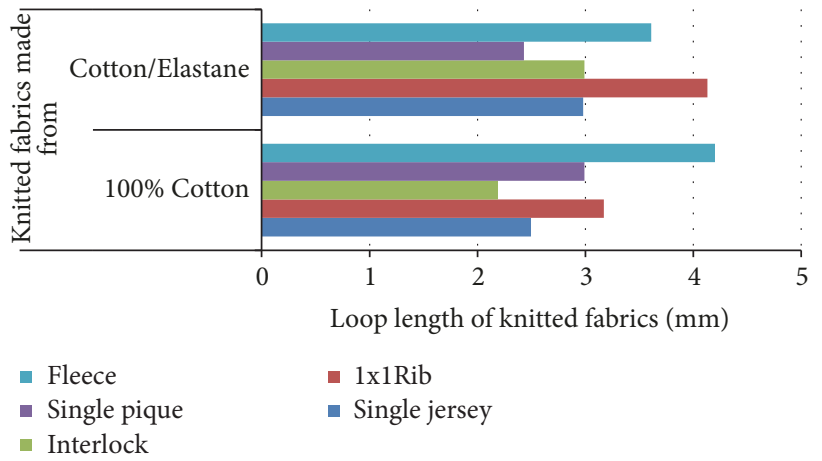

FIgURE 1: Loop lengths of knitted fabrics made from $100 \%$ cotton and cotton/elastane yarns.

$$
\begin{aligned}
& \text { loop pitch }= \frac{1}{\mathrm{cpc} * \mathrm{wpc}}, \\
& \mathrm{cpc} * \mathrm{wpc}=\mathrm{s} \text { (stitch density) } \\
& T=\frac{1}{\mathrm{~s}}
\end{aligned}
$$

\section{Result and Discussion}

3.1. Knitted Fabric Loop Length. Loop length of single jersey, 1xlrib, interlock, single pique, and fleece knitted fabrics has been studied and the results are shown in Figure 1.

As shown in Figure 1, the loop length of single jersey, $1 \times 1$ rib, interlock, single pique, and fleece knitted fabrics made from $100 \%$ cotton and cotton/elastane (95/5\%) blended yarns is different. Single jersey, 1xlrib, and interlock knitted fabrics made from $100 \%$ cotton have lower loop length as compared to the same fabrics made from cotton/elastane blended yarn while single pique and fleece knitted fabrics made from $100 \%$ cotton have higher loop length as compared to the same fabrics made from cotton/elastane blended yarns. The loop length of 1xlrib knitted fabric made from cotton/elastane yarn is the highest as compared to other knitted fabrics made from the same yarns while fleece made from $100 \%$ cotton has the highest loop length as compared to other fabrics made from the same yarns. This is because in 1xlrib knitted fabrics the yarn is pulled by two needles in opposite directions. Though the pulling forces applied to the yarn are equal the two yarns are not pulled equally with the same amount of force. With this regard cotton/elastane yarn gives high loop length in 1xlrib knitted fabrics as compared to the other knitted fabrics made from the same yarns, but this is not working for interlock because interlock is made when two 1xlrib loops are locked together to form a four-loop interlock. The lowest loop length is observed in two-thread fleece knitted fabrics made from cotton/elastane blended yarn. This is because in two-thread fleece knitted fabrics two threads are floating at the technical back of the fabrics which limits the loop length from the main thread (ground thread).

In Table 1, the mean, standard deviation, standard error, and minimum and maximum values of the test specimens are shown. The standard deviations of all sampled fabrics made from $100 \%$ cotton and cotton/elastane are similar with slight deviations from their mean. This shows that the values in a statistical data set are closest to the mean of the data set, on average.

The loop length of single jersey, 1xlrib, interlock, single pique, and fleece knitted fabrics mean differences are significant at 0.05 levels. As shown in Table 2, the loop length of single jersey is significantly influenced by the presence of $5 \%$ elastane in the Upper Awash combed cotton yarn $(\mathrm{F}=6.309$; Sig. = 0.022000). 1x1Rib ( $F=9.026$; Sig. = 0.008000), interlock $(\mathrm{F}=442.312$; Sig. $=0.000000)$, single pique $(\mathrm{F}=7.649$; Sig. $=0.013000)$, and fleece $(F=30704.168$; Sig. $=0.000000)$ knitted fabrics are significantly influenced by elastane yarns. Fleece has the greatest F-value as compared to other knitted fabrics, and this shows that fleece has a high dispersion rate as compared to other knitted fabrics.

3.2. Wales and Courses Per Unit Length. The wales and courses per unit length of single jersey, 1xlrib, interlock, single pique, and fleece knitted fabrics have been studied and the results are shown in Figures 2 and 3. The wales and courses per unit length of these fabrics were measured using pick glass to count the course per centimeter and wales per centimeter and abbreviated as cpc and wpc, respectively.

As shown in Figures 2 and 3, the wpc and cpc of single jersey, $1 \times 1$ rib, interlock, single pique, and fleece knitted fabrics made from $100 \%$ cotton and cotton/elastane $(95 / 5 \%)$ blended yarns are different. Single jersey, 1xlrib, interlock, single pique, and fleece knitted fabrics made from $100 \%$ cotton have lower wpc as compared to the same fabrics made from cotton/elastane blended yarn. The wpc of interlock knitted fabric made from cotton/elastane yarn is the highest as compared to other knitted fabrics made from the same yarn while two-thread fleece made from cotton/elastane has the lowest wpc as compared to other knitted fabrics made from the same yarns. Similarly, the cpc of single jersey made from both $100 \%$ cotton and cotton/elastane yarns is the highest as compared to the other fabrics made from the same materials. Interlock knitted fabric has the lowest cpc as compared to other knitted fabrics because the interlock knitted fabric is made when two 1xlrib structures locked together.

The wpc of single jersey, 1xlrib, interlock, single pique, and fleece knitted fabrics is increased due to the presence of $5 \%$ elastane in $95 \%$ cotton yarns as compared to the same 
TABLE 1: Description for loop lengths of knitted fabrics made from $100 \%$ cotton and cotton/elastane yarns.

\begin{tabular}{|c|c|c|c|c|c|c|c|}
\hline & & $\mathrm{N}$ & Mean & Std. Deviation & Std. Error & Minimum & Maximum \\
\hline \multirow{3}{*}{ Loop length of single jersey } & 95.00 & 10 & 2.9820 & .05712 & .01806 & 2.86 & 3.05 \\
\hline & 100.00 & 10 & 3.0360 & .03688 & .01166 & 3.00 & 3.09 \\
\hline & Total & 20 & 3.0090 & .05438 & .01216 & 2.86 & 3.09 \\
\hline \multirow{3}{*}{ Loop length of 1xlrib } & 95.00 & 10 & 4.1270 & .97313 & .30773 & 3.49 & 5.55 \\
\hline & 100.00 & 10 & 3.1710 & .25614 & .08100 & 3.09 & 3.90 \\
\hline & Total & 20 & 3.6490 & .84862 & .18976 & 3.09 & 5.55 \\
\hline \multirow{3}{*}{ Loop length of interlock } & 95.00 & 10 & 2.9880 & .02251 & .00712 & 2.95 & 3.03 \\
\hline & 100.00 & 10 & 2.1910 & .11770 & .03722 & 2.04 & 2.33 \\
\hline & Total & 20 & 2.5895 & .41709 & .09326 & 2.04 & 3.03 \\
\hline \multirow{3}{*}{ Loop length of pique } & 95.00 & 10 & 2.4350 & .63458 & .20067 & .63 & 2.66 \\
\hline & 100.00 & 10 & 2.9900 & .00000 & .00000 & 2.99 & 2.99 \\
\hline & Total & 20 & 2.7125 & .52135 & .11658 & .63 & 2.99 \\
\hline \multirow{3}{*}{ Loop length of fleece } & 95.00 & 10 & 3.6130 & .01059 & .00335 & 3.60 & 3.63 \\
\hline & 100.00 & 10 & 4.2000 & .00000 & .00000 & 4.20 & 4.20 \\
\hline & Total & 20 & 3.9065 & .30121 & .06735 & 3.60 & 4.20 \\
\hline
\end{tabular}

TABLE 2: Analysis of variances of knitted fabrics loop length made from $100 \%$ cotton and cotton/elastane.

\begin{tabular}{|c|c|c|c|c|c|c|}
\hline & & Sum of Squares & Df & Mean Square & $\mathrm{F}$ & Sig. \\
\hline \multirow{3}{*}{ Loop length of single jersey } & Between Groups & .015 & 1 & .015 & 6.309 & .022 \\
\hline & Within Groups & .042 & 18 & .002 & & \\
\hline & Total & .056 & 19 & & & \\
\hline \multirow{3}{*}{ Loop length of 1x1rib } & Between Groups & 4.570 & 1 & 4.570 & 9.026 & .008 \\
\hline & Within Groups & 9.113 & 18 & .506 & & \\
\hline & Total & 13.683 & 19 & & & \\
\hline \multirow{3}{*}{ Loop length of interlock } & Between Groups & 3.176 & 1 & 3.176 & 442.312 & .000 \\
\hline & Within Groups & .129 & 18 & .007 & & \\
\hline & Total & 3.305 & 19 & & & \\
\hline \multirow{3}{*}{ Loop length of pique } & Between Groups & 1.540 & 1 & 1.540 & 7.649 & .013 \\
\hline & Within Groups & 3.624 & 18 & .201 & & \\
\hline & Total & 5.164 & 19 & & & \\
\hline \multirow{3}{*}{ Loop length of fleece } & Between Groups & 1.723 & 1 & 1.723 & 30704.168 & .000 \\
\hline & Within Groups & .001 & 18 & .000 & & \\
\hline & Total & 1.724 & 19 & & & \\
\hline
\end{tabular}

fabrics made from $100 \%$ cotton. But, cpc of some of the fabrics such as interlock and 1xlrib is reduced and cpc of some of the fabrics such as single jersey, single pique, and fleece is increased due to the presence of $5 \%$ elastane yarn in $95 \%$ cotton yarn. This is due to the high shrinkage rate differences of these fabrics due to the presence of elastane yarns in the structures.

The ascending order of wpc of the five knit structures made from cotton/elastane blended yarns is two-thread fleece, single pique, single jersey, 1xlrib, and interlock knitted fabrics (see Figure 2) while fleece, 1xlrib, single pique, interlock, and single jersey is an ascending order wpc of knitted fabrics made from $100 \%$ yarn. An ascending order of cpc of knitted fabrics made from $100 \%$ cotton and cotton/elastane blended yarns is interlock, 1xlrib, single pique, fleece, and single jersey. In Tables 3 and 4, the mean, standard deviation, standard error, and minimum and maximum values of test specimens are shown. The standard deviations of all sampled fabrics made from $100 \%$ cotton and cotton/elastane are similar with slight deviations from their mean. This shows that the values in a statistical data set are closest to the mean of the data set, on average.

The wpc and cpc of single jersey, 1xlrib, interlock, single pique, and fleece knitted fabrics mean differences are significant at 0.05 levels. As shown in Table 5, the wpc of single jersey is significantly influenced by the presence of $5 \%$ elastane in the Upper Awash combed cotton yarn $(\mathrm{F}=222.618$; Sig. = 0.000000). 1xlRib $(F=874.975$; Sig. $=0.000000)$, interlock $(\mathrm{F}=611.861$; Sig. $=0.000000)$, single pique $(\mathrm{F}=859.260$; Sig. $=0.000000)$, and fleece $(F=674.165$; Sig. $=0.000000)$ knitted fabrics are significantly influenced by elastane yarns. Fleece has greater F-value as compared to other knitted fabrics which shows that fleece has a high dispersion rate as compared to other knitted fabrics. 


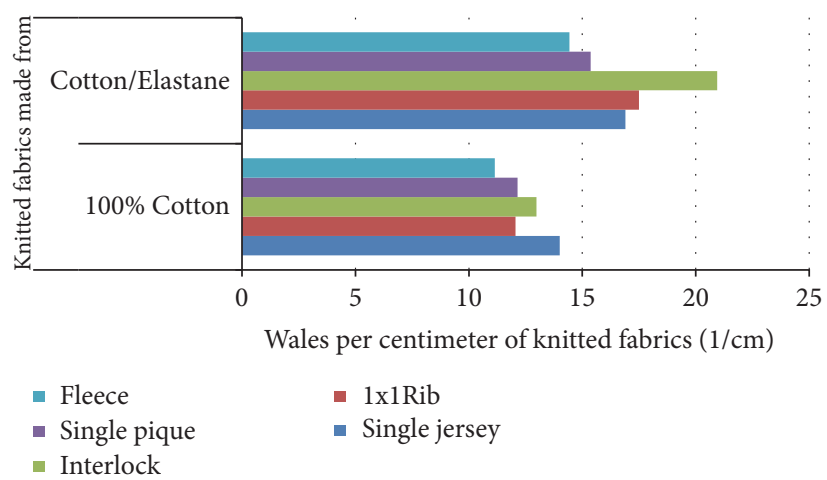

FIGURE 2: Wales per centimeter of knitted fabrics made from $100 \%$ cotton and cotton/elastane yarns.

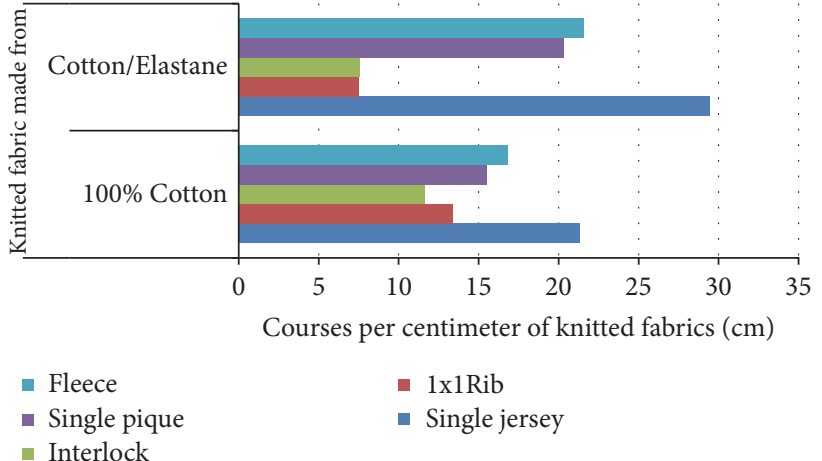

FIGURE 3: Courses per centimeter (cpc) of knitted fabrics made from 100\% cotton and cotton/elastane yarns.

As shown in Table 6, the cpc of single jersey is significantly influenced by the presence of 5\% elastane in the Upper Awash combed cotton yarn $(\mathrm{F}=1026.939$; Sig. $=0.000000)$. $1 \mathrm{x} 1 \mathrm{Rib}$ $(F=765.224$; Sig. $=0.000000)$, interlock $(F=334.884$; Sig. $=0.000000)$, single pique $(\mathrm{F}=421.299$; Sig. $=0.000000)$, and fleece $(F=414.720$; Sig. $=0.000000)$ knitted fabrics are significantly influenced by elastane yarns. Single jersey has the highest F-value as compared to other knitted fabrics which shows that single jersey has a high dispersion rate as compared to other knitted fabrics.

3.3. Stitch Density. The stitch density per unit area of single jersey, 1xlrib, interlock, single pique, and fleece knitted fabrics has been studied and the results are shown in Figure 4 .

As shown in Figure 4, the stitch density of single jersey, $1 \times 1$ rib, interlock, single pique, and fleece knitted fabrics made from $100 \%$ cotton and cotton/elastane (95/5\%) blended yarns is different. Single jersey, 1xlrib, interlock, single pique, and fleece knitted fabrics made from $100 \%$ cotton have the lowest stitch density as compared to the single jersey, single pique, and fleece made from cotton/elastane blended yarn. 1xiRib and interlock knitted fabrics made from cotton/elastane yarn have the lowest stitch density as compared to other fabrics made from the same materials. This is because cpc of 1xlrib and interlock are lower than other fabrics made from cotton/elastane yarns.

The presence of $5 \%$ elastane yarn in $95 \%$ cotton yarn influences the stitch density of knitted fabrics. The stitch density single jersey, single pique, and fleece knitted fabrics increased due to the presence of 5\% elastane in 95\% cotton yarns whereas the stitch density of 1xlrib and interlock knitted fabrics decreased. An ascending order of stitch density of knitted fabrics made from cotton/elastane blended yarns is 1xlrib, interlock, single pique, fleece, and single jersey.

3.4. Tightness Factor. The tightness factor of single jersey, 1xlrib, interlock, single pique, and fleece knitted fabrics has been studied and the results are shown in Figure 5.

The tightness factor of single jersey, $1 \times 1 \mathrm{rib}$, interlock, single pique, and fleece knitted fabrics made from $100 \%$ cotton and cotton/elastane (95/5\%) blended yarns is different. The two-thread fleece and 1xlrib knitted fabrics made from $100 \%$ cotton and cotton/elastane blended yarns have the lowest stitch density as compared to other fabrics made from the same yarns. Interlock knitted fabric made from $100 \%$ cotton is the tightest as compared to other fabrics made from $100 \%$ cotton and cotton/elastane yarns. The tightness factor of knitted fabrics had a different influence due to the presence of $5 \%$ elastane yarns in the $95 \%$ cotton yarns. The tightness of interlock, single jersey, and 1xlrib knitted fabrics decreased with cotton/elastane yarns while single pique and two-thread fleece knitted fabrics increased with the same yarn.

3.5. Loop Shape Factor. The loop shape factor of single jersey, 1xlrib, interlock, single pique, and fleece knitted fabrics has been studied and the results are shown in Figure 6. 
TABLE 3: Description for wpc of knitted fabrics made from $100 \%$ cotton and cotton/elastane yarns.

\begin{tabular}{|c|c|c|c|c|c|c|c|}
\hline & & $\mathrm{N}$ & Mean & Std. Deviation & Std. Error & Minimum & Maximum \\
\hline \multirow{3}{*}{ Wales per centimeter of single jersey } & 95.00 & 10 & 16.9000 & .39441 & .12472 & 16.50 & 17.50 \\
\hline & 100.00 & 10 & 14.0000 & .47140 & 14907 & 13.50 & 14.50 \\
\hline & Total & 20 & 15.4500 & 1.54664 & .34584 & 13.50 & 17.50 \\
\hline \multirow{3}{*}{ Wales per centimeter of $1 x 1$ rib } & 95.00 & 10 & 17.5000 & .52705 & .16667 & 17.00 & 18.00 \\
\hline & 100.00 & 10 & 12.0600 & .24585 & .07775 & 11.80 & 12.50 \\
\hline & Total & 20 & 14.7800 & 2.81922 & .63040 & 11.80 & 18.00 \\
\hline \multirow{3}{*}{ Wales per centimeter of interlock } & 95.00 & 10 & 20.9400 & 1.00687 & .31840 & 20.00 & 23.00 \\
\hline & 100.00 & 10 & 12.9800 & .14757 & .04667 & 12.80 & 13.20 \\
\hline & Total & 20 & 16.9600 & 4.14302 & .92641 & 12.80 & 23.00 \\
\hline \multirow{3}{*}{ Wales per centimeter of pique } & 95.00 & 10 & 15.3700 & .30569 & .09667 & 15.00 & 15.80 \\
\hline & 100.00 & 10 & 12.1500 & .16499 & .05217 & 12.00 & 12.40 \\
\hline & Total & 20 & 13.7600 & 1.66904 & .37321 & 12.00 & 15.80 \\
\hline \multirow{3}{*}{ Wales per centimeter of fleece } & 95.00 & 10 & 14.4300 & .31640 & .10006 & 14.00 & 14.90 \\
\hline & 100.00 & 10 & 11.1400 & .24585 & .07775 & 10.90 & 11.60 \\
\hline & Total & 20 & 12.7850 & 1.71012 & .38239 & 10.90 & 14.90 \\
\hline
\end{tabular}

TABLE 4: Description for the cpc of knitted fabrics made from $100 \%$ cotton and cotton/elastane yarns.

\begin{tabular}{|c|c|c|c|c|c|c|c|}
\hline & & $\mathrm{N}$ & Mean & Std. Deviation & Std. Error & Minimum & Maximum \\
\hline \multirow{3}{*}{ Courses per centimeter of single jersey } & 95.00 & 10 & 29.4500 & .43780 & .13844 & 29.00 & 30.00 \\
\hline & 100.00 & 10 & 21.3500 & .66875 & .21148 & 20.00 & 22.00 \\
\hline & Total & 20 & 25.4000 & 4.19147 & .93724 & 20.00 & 30.00 \\
\hline \multirow{3}{*}{ Courses per centimeter of 1xlrib } & 95.00 & 10 & 7.5000 & .47140 & .14907 & 7.00 & 8.00 \\
\hline & 100.00 & 10 & 13.3500 & .47434 & .15000 & 13.00 & 14.00 \\
\hline & Total & 20 & 10.4250 & 3.03608 & 67889 & 7.00 & 14.00 \\
\hline \multirow{3}{*}{ Courses per centimeter of interlock } & 95.00 & 10 & 7.6000 & .51640 & .16330 & 7.00 & 8.00 \\
\hline & 100.00 & 10 & 11.6000 & .45947 & .14530 & 11.00 & 12.00 \\
\hline & Total & 20 & 9.6000 & 2.10638 & .47100 & 7.00 & 12.00 \\
\hline \multirow{3}{*}{ Courses per centimeter of pique } & 95.00 & 10 & 20.3500 & .57975 & .18333 & 20.00 & 21.50 \\
\hline & 100.00 & 10 & 15.5000 & .47140 & .14907 & 15.00 & 16.00 \\
\hline & Total & 20 & 17.9250 & 2.54059 & .56809 & 15.00 & 21.50 \\
\hline \multirow{3}{*}{ Courses per centimeter of fleece } & 95.00 & 10 & 21.6000 & .45947 & .14530 & 21.00 & 22.00 \\
\hline & 100.00 & 10 & 16.8000 & .58689 & .18559 & 16.00 & 17.50 \\
\hline & Total & 20 & 19.2000 & 2.51522 & .56242 & 16.00 & 22.00 \\
\hline
\end{tabular}

TABLE 5: Analysis of variances of knitted fabrics wpc made from $100 \%$ cotton and cotton/elastane yarns.

\begin{tabular}{|c|c|c|c|c|c|c|}
\hline & & Sum of Squares & $\mathrm{Df}$ & Mean Square & $\mathrm{F}$ & Sig. \\
\hline \multirow{3}{*}{ Wales per centimeter of single jersey } & Between Groups & 42.050 & 1 & 42.050 & 222.618 & .000 \\
\hline & Within Groups & 3.400 & 18 & .189 & & \\
\hline & Total & 45.450 & 19 & & & \\
\hline \multirow{3}{*}{ Wales per centimeter of 1 xlrib } & Between Groups & 147.968 & 1 & 147.968 & 874.975 & .000 \\
\hline & Within Groups & 3.044 & 18 & .169 & & \\
\hline & Total & 151.012 & 19 & & & \\
\hline \multirow{3}{*}{ Wales per centimeter of interlock } & Between Groups & 316.808 & 1 & 316.808 & 611.861 & .000 \\
\hline & Within Groups & 9.320 & 18 & .518 & & \\
\hline & Total & 326.128 & 19 & & & \\
\hline \multirow{3}{*}{ Wales per centimeter of pique } & Between Groups & 51.842 & 1 & 51.842 & 859.260 & .000 \\
\hline & Within Groups & 1.086 & 18 & .060 & & \\
\hline & Total & 52.928 & 19 & & & \\
\hline \multirow{3}{*}{ Wales per centimeter of fleece } & Between Groups & 54.120 & 1 & 54.120 & 674.165 & .000 \\
\hline & Within Groups & 1.445 & 18 & .080 & & \\
\hline & Total & 55.565 & 19 & & & \\
\hline
\end{tabular}


TABLE 6: Analysis of variances of knitted fabrics cpc made from $100 \%$ cotton and cotton/elastane yarns.

\begin{tabular}{|c|c|c|c|c|c|c|}
\hline & & Sum of Squares & $\mathrm{df}$ & Mean Square & $\mathrm{F}$ & Sig. \\
\hline \multirow{3}{*}{ Courses per centimeter of single jersey } & Between Groups & 328.050 & 1 & 328.050 & 1026.939 & .000000 \\
\hline & Within Groups & 5.750 & 18 & .319 & & \\
\hline & Total & 333.800 & 19 & & & \\
\hline \multirow{3}{*}{ Courses per centimeter of 1x1rib } & Between Groups & 171.113 & 1 & 171.113 & 765.224 & .000000 \\
\hline & Within Groups & 4.025 & 18 & .224 & & \\
\hline & Total & 175.138 & 19 & & & \\
\hline \multirow{3}{*}{ Courses per centimeter of interlock } & Between Groups & 80.000 & 1 & 80.000 & 334.884 & .000000 \\
\hline & Within Groups & 4.300 & 18 & .239 & & \\
\hline & Total & 84.300 & 19 & & & \\
\hline \multirow{3}{*}{ Courses per centimeter of pique } & Between Groups & 117.613 & 1 & 117.613 & 421.299 & .000000 \\
\hline & Within Groups & 5.025 & 18 & .279 & & \\
\hline & Total & 122.638 & 19 & & & \\
\hline \multirow{3}{*}{ Courses per centimeter of fleece } & Between Groups & 115.200 & 1 & 115.200 & 414.720 & .000000 \\
\hline & Within Groups & 5.000 & 18 & .278 & & \\
\hline & Total & 120.200 & 19 & & & \\
\hline
\end{tabular}

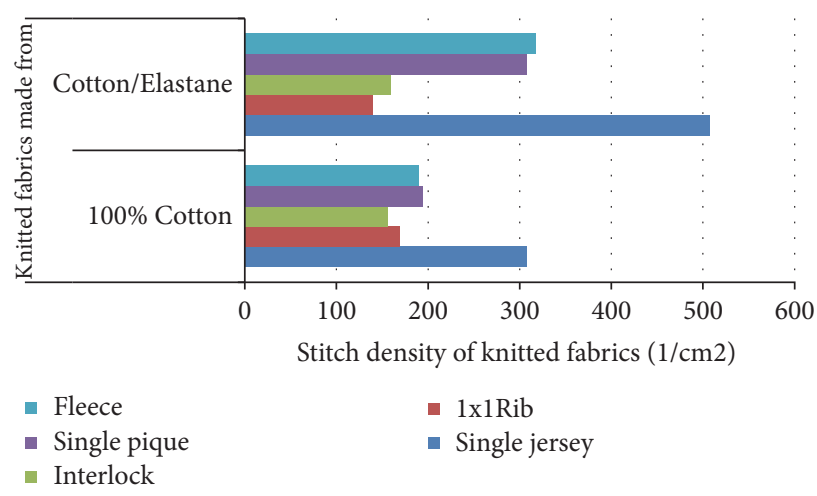

FIGURE 4: Stitch density of knitted fabrics made from $100 \%$ cotton and cotton/elastane yarns.

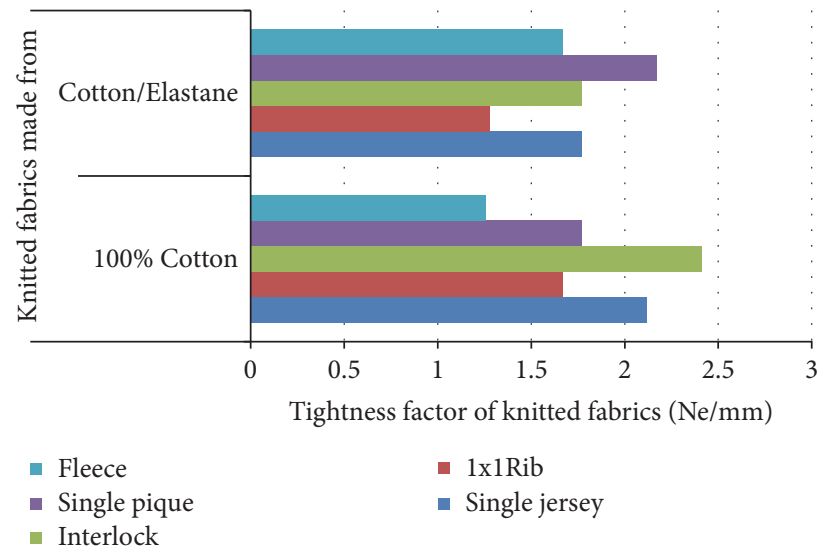

FIgURE 5: Tightness factor of knitted fabrics made from $100 \%$ cotton and cotton/elastane yarns.

The loop shape factor of single jersey, $1 \times 1$ rib, interlock, single pique, and fleece knitted fabrics made from $100 \%$ cotton and cotton/elastane (95/5\%) blended yarns is different. The loop shape factor of fleece knitted fabric is not changed due to elastane yarn. Interlock and 1x1rib knitted fabric's loop shape factor reduced due to elastane content in cotton yarn. Only single jersey knitted fabric has significant change in increasing due to $5 \%$ elastane yarn in $95 \%$ cotton while 1xlrib and interlock are decreasing. Single pique shows a slight change in the reduction of loop shape factor because of the 


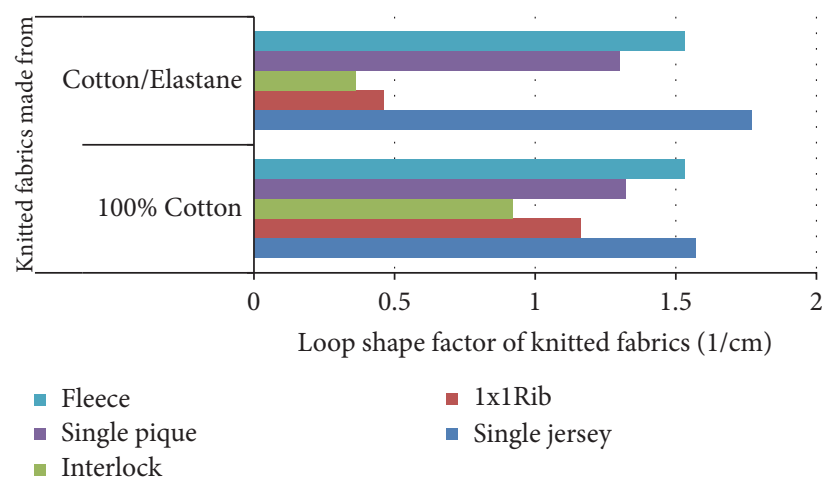

FIGURE 6: Loop shape factor of knitted fabrics made from 100\% cotton and cotton/elastane yarns.

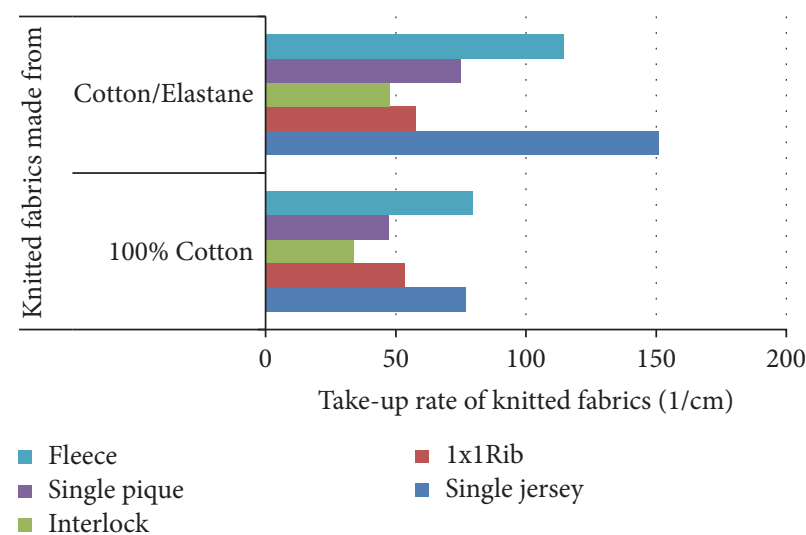

Figure 7: Take-up rate of knitted fabrics made from 100\% cotton and cotton/elastane yarns.

presence of $5 \%$ elastane yarn in $95 \%$ cotton. So, the loop shape of knitted fabrics made from $100 \%$ cotton and cotton/elastane yarns had a different influence due to structural stability, needle working, and idle time in each structure.

3.6. Take-Up Rate. The take-up rate of single jersey, 1xlrib, interlock, single pique, and fleece knitted fabrics has been studied and the results are shown in Figure 7.

The take-up rate of single jersey, $1 \times 1$ rib, interlock, single pique, and fleece knitted fabrics made from $100 \%$ cotton and cotton/elastane (95/5\%) blended yarns is different. The takeup rate of single jersey, 1xlrib, single pique, interlock, and twothread fleece knitted fabrics made from $100 \%$ cotton is lower as compared to the same fabrics made from cotton/elastane blended yarns. Take-up rate of knitted fabrics is inversely proportional to stitch density and directly to loop length. Low take-up rate of knitted fabrics means that knitted fabric is with low loop length and high stitch density and vice versa. An ascending order of take-up rate of knitted fabrics made from cotton/elastane blended yarn is interlock, 1xlrib, single pique, two-thread fleece, and single jersey knitted fabrics.

\section{Conclusion}

The dimensional characteristics of five knitted structures made from $100 \%$ cotton and $95 \%$ cotton $/ 5 \%$ elastane blended yarns were studied. As investigated in the results and discussion, the loop lengths of the primary knitted fabrics such as single jersey, 1xlrib, and 1xlinterlock knitted fabrics made from cotton/elastane yarn have been increased for the needles were able to frequently receive new loop and release an old loop during knitting. The other fabric properties such as wales per centimeter (wpc), courses per centimeter (cpc), stitch density (s), tightness factor (K), take-up rate $(\mathrm{T})$, and loop shape factor $(\mathrm{R})$ are significantly influenced by the presence of elastane yarns in the knitted fabrics.

The dimensional properties are interrelated to each other. Once the loop length is influenced by the presence of elastane yarns it is obvious that other characteristics are influenced. From this research, it is observed that the other dimensional properties (except take-up rate) are inversely proportional to loop length. wpc and cpc of the knitted fabrics depend on loop length, shrinkage, and action of sets of the needles. On the other hand, stitch density, loop shape factor, and take-up rate of knitted fabrics depend on wpc and cpc in addition to loop length, as shown in the results of this research.

\section{Data Availability}

The data used to support the findings of this study are cited in the article. 


\section{Conflicts of Interest}

The author declares that he has no conflicts of interest.

\section{Acknowledgments}

This research is completed with the help of MAA Garment and Textile Factory (located in Mekelle, Ethiopia) and the Ethiopian Institute of Textile and Fashion Technology (EiTEX, Bahir Dar University, Bahir Dar, Ethiopia). The staff of these organizations have been the core investigators for this fruitful work. The author would like to thank them for their effort and cooperation.

\section{References}

[1] M. Szabo, M. Dochia, and M. Lungu, "Research study on the dimensional stability of interlock 1:1 knitted fabrics made of cotton yarns," Scientific Research and Education in the Air Force, vol. 18, no. 1, pp. 367-376, 2016.

[2] J. Abramavičiute, D. Mikučioniene, and R. Čiukas, "Structure properties of knits from natural yarns and their combination with elastane and polyamide threads," Materials Science, vol. 17, no. 1, pp. 43-46, 2011.

[3] Y. Beceren, C. Candan, S. Cimilli, and K. Ülger, "Properties of plain knits from siro-spun viscose/spandex yarns," Fibres \& Textiles in Eastern Europe, vol. 18, no. 1, pp. 41-46, 2010.

[4] A. B. Marmarali, "Dimensional and physical properties of cotton/spandex single jersey fabrics," Textile Research Journal, vol. 73, no. 12, pp. 11-14, 2003.

[5] C. N. Herath, B. C. Kang, and H.-Y. Jeon, "Dimensional stability of cotton-spandex interlock structures under relaxation," Fibers and Polymers, vol. 8, no. 1, pp. 105-110, 2007.

[6] F. Spandex, Fiber Source, http://www.fibersource.com/ftutor/, 2015.

[7] S. J. Kadolph, Textiles. 10 ed2009: India, Dorling Kindersley India Pvt Ltd.

[8] M. K. Bardhan, "Anatomy of sportswear and leisurewear," in Man Made Text India, vol. 8, 1 edition, 2004.

[9] J. E. Luke, Stretch Challenge, Textile World, 2002.

[10] S. Tezel and Y. Kavuşturan, "Experimental investigation of effects of spandex brand and tightness factor on dimensional and physical properties of cotton/spandex single jersey fabrics," Textile Research Journal, vol. 78, no. 11, pp. 966-976, 2008.

[11] E. A. E. Eltahan, M. Sultan, and A.-B. Mito, "Determination of loop length, tightness factor and porosity of single jersey knitted fabric," Alexandria Engineering Journal, vol. 55, no. 2, pp. 851856, 2016.

[12] C. N. Herath and B. C. Kang, "Dimensional stability of core spun cotton/spandex single jersey fabrics under relaxation," Textile Research Journal, vol. 78, no. 3, pp. 209-216, 2008.

[13] A. Bayazit, "Dimensional and physical properties of cotton/spandex single jersey fabrics," Textile Research Journal, vol. 73, pp. 11-14, 2003.

[14] R. Sadek, A. M. El-Hossini, A. S. Eldeeb, and A. A. Yassen, "Effect of lycra extension percent on single jersey knitted fabric properties," Journal of Engineered Fibers and Fabrics, vol. 7, no. 2, pp. 11-16, 2012.

[15] C. N. Herath and B. C. Kang, "Dimensional characteristics of core spun cotton-spandex $1 \times 1$ rib knitted fabrics in laundering,"
International Journal of Clothing Science and Technology, vol. 19, no. 1, pp. 43-58, 2007.

[16] C. Prakash and K. Thangamani, "Establishing the effect of loop length on dimensional stability of single jersey knitted fabric made from cotton/lycra core spun yarn," Indian Journal of Science and Technology, vol. 3, no. 3, pp. 287-289, 2010.

[17] S. B. Abdessalem, Y. B. Abdelkader, S. Mokhtar, and S. Elmarzougui, "Influence of elastane consumption on plated plain knitted fabric characteristics," Journal of Engineered Fibers and Fabrics, vol. 4, no. 4, pp. 30-35, 2009.

[18] D. J. Spencer, Knitting Technology: A Comprehensive Handbook and Practical Guide, vol. 105, Woodhead Publishing Limited, England, UK, 3rd edition, 2001. 


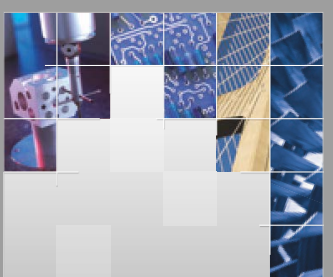

\section{Enfincering}
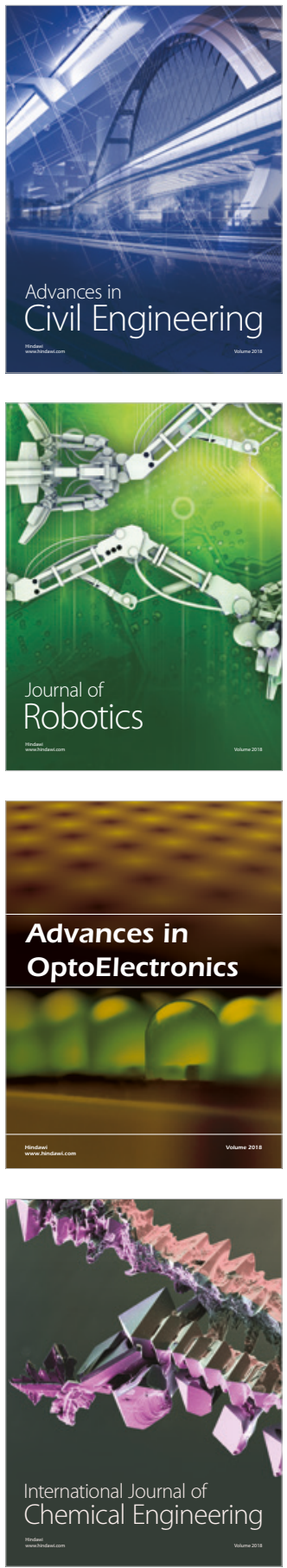

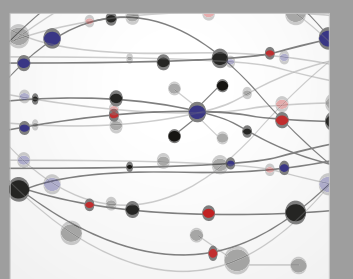

\section{Rotating \\ Machinery}

The Scientific World Journal

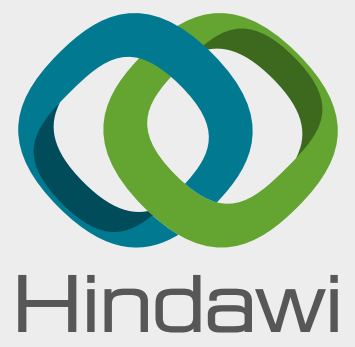

Submit your manuscripts at

www.hindawi.com
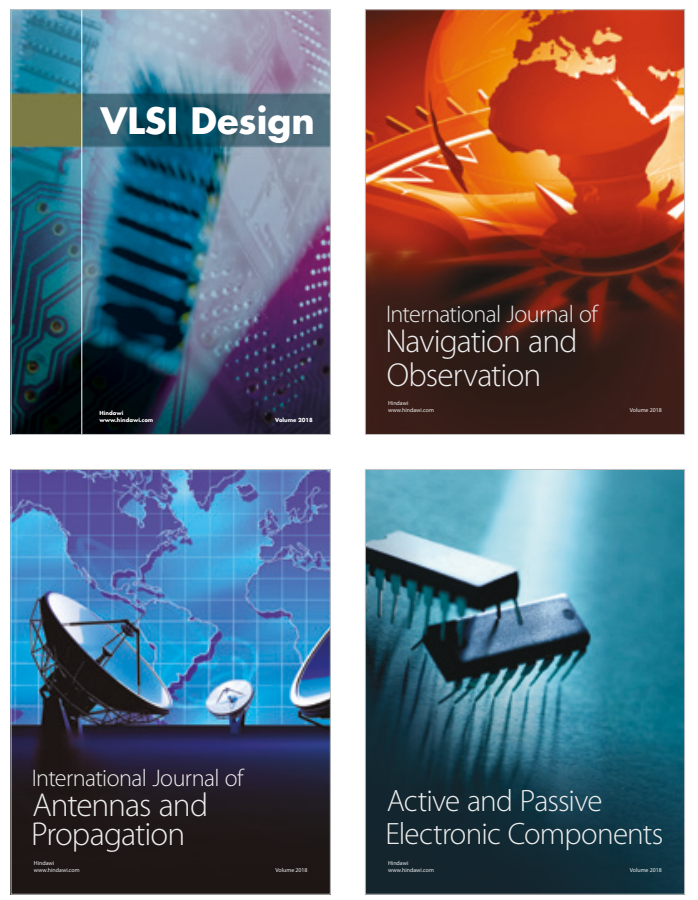
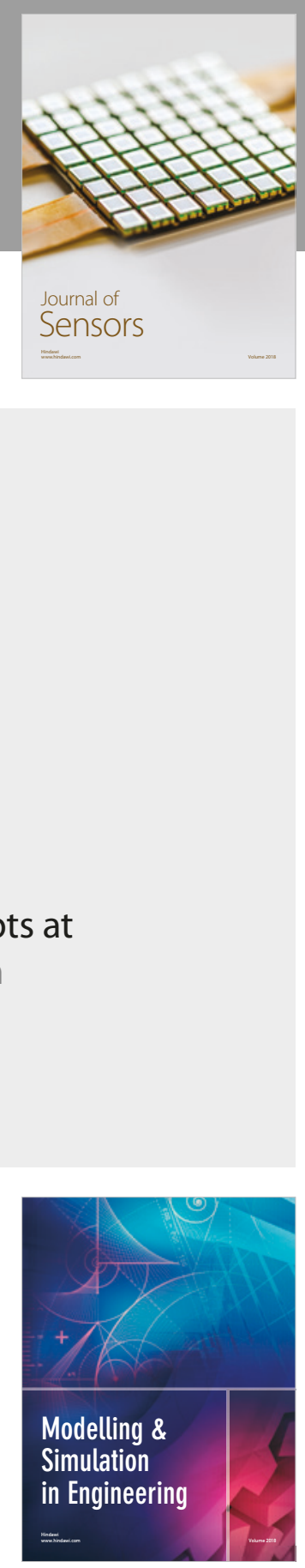

\section{Advances \\ Multimedia}
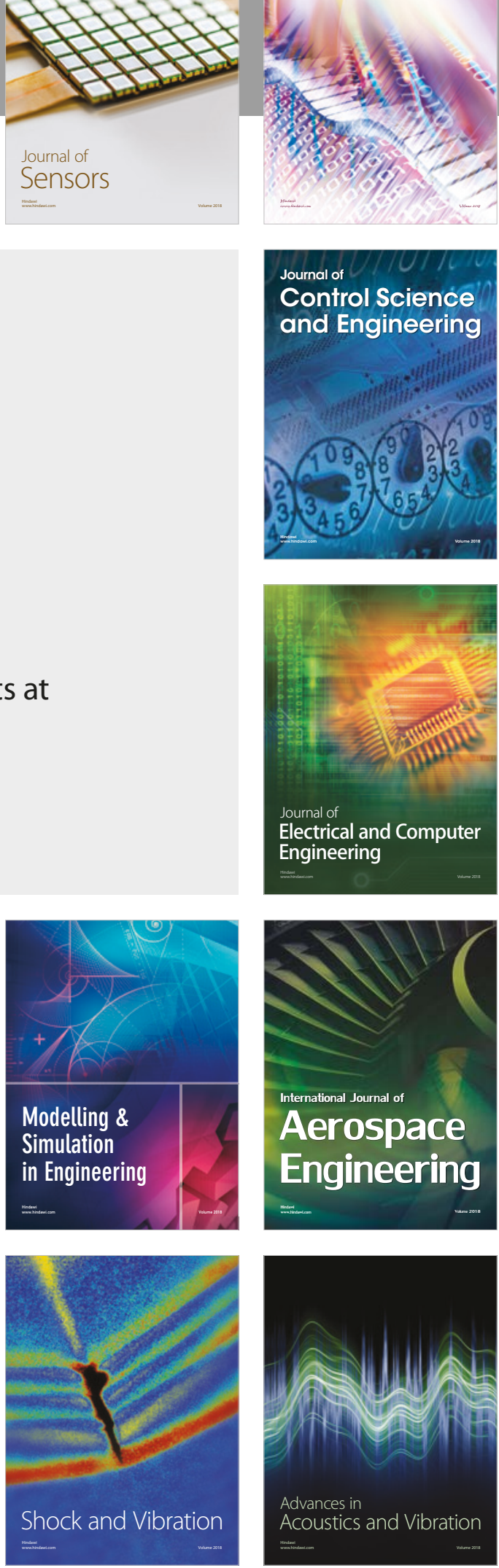